\title{
Cost of childhood acute otitis media in primary care in the Netherlands: economic analysis alongside a cluster randomised controlled trial
}

Rick T. van Uum ${ }^{1 *}$ (D), Roderick P. Venekamp ${ }^{1}$, Clémence T. B. Pasmans ${ }^{1}$, G. Ardine de Wit ${ }^{1,2}$, Alies Sjoukes ${ }^{1}$, Alma C. van der Pol', Roger A. M. J. Damoiseaux ${ }^{1}$ and Anne G. M. Schilder ${ }^{1,3,4}$

\begin{abstract}
Background: Acute otitis media (AOM) is among the most common paediatric conditions managed in primary care. Most recent estimates of the cost of AOM date from a decade ago and lack a full societal perspective. We therefore explored the societal cost of childhood AOM in the Netherlands within the setting of a trial comparing the effectiveness of an intervention aimed at educating general practitioners (GPs) about pain management in AOM compared to usual care.
\end{abstract}

Methods: Economic analysis alongside a cluster randomised controlled trial conducted between February 2015 and May 2018 in 37 practices (94 GPs). In total, 224 children with AOM were included of which 223 (99\%) completed the trial (intervention: $n=94$; control: $n=129$ ). The cost of AOM due to health care costs, patient and family costs, and productivity losses by parent caregivers were retrieved from study diaries and primary care electronic health records, during 28-day follow-up. We calculated mean cost ( $€$ and \$) per AOM episode per patient with standard deviations (SD, in $€$ ) regardless of study group assignment because there was no clinical effect of the trial intervention. In sensitivity analysis, we calculated cost in the intervention and usual care group, after exclusion of extreme outliers.

Results: Mean total AOM cost per patient were $€ 565.93$ or $\$ 638.78$ (SD $€ 1071.01$ ); nearly $90 \%$ of these costs were due to productivity losses experienced by parents. After exclusion of outliers, AOM cost was $€ 526.70$ or $\$ 594.50$ (SD $€ 987.96$ ) and similar in the intervention and usual care groups: $€ 516.10$ or $\$ 582.53$ (SD €949.69) and $€ 534.55$ or $\$ 603.36$ (SD €920.55) respectively.

Conclusions: At $€ 566$ or $\$ 639$ per episode, societal cost of AOM is higher than previously known and mainly driven by productivity losses by children's parents. Considering its high incidence, AOM poses a significant economic burden that extends beyond direct medical costs.

(Continued on next page)

\footnotetext{
* Correspondence: R.T.vanUum-2@umcutrecht.nl

'Julius Center for Health Sciences and Primary Care, University Medical

Center Utrecht, University Utrecht, P.O. Box 85500, 3508, GA, Utrecht, The Netherlands

Full list of author information is available at the end of the article
}

(c) The Author(s). 2021 Open Access This article is licensed under a Creative Commons Attribution 4.0 International License, which permits use, sharing, adaptation, distribution and reproduction in any medium or format, as long as you give appropriate credit to the original author(s) and the source, provide a link to the Creative Commons licence, and indicate if changes were made. The images or other third party material in this article are included in the article's Creative Commons licence, unless indicated otherwise in a credit line to the material. If material is not included in the article's Creative Commons licence and your intended use is not permitted by statutory regulation or exceeds the permitted use, you will need to obtain permission directly from the copyright holder. To view a copy of this licence, visit http://creativecommons.org/licenses/by/4.0/ The Creative Commons Public Domain Dedication waiver (http://creativecommons.org/publicdomain/zero/1.0/) applies to the data made available in this article, unless otherwise stated in a credit line to the data. 
(Continued from previous page)

Trial registration: Netherlands Trial Register no. NTR4920: http://www.trialregister.nl/trialreg/admin/rctview.asp?TC= 4920.

Keywords: Acute otitis media, Pain management, Healthcare resources use, Societal cost of AOM

\section{What's known on this subject}

Most recent estimates of the cost of acute otitis media (AOM), a common paediatric condition, date from a decade ago and lack a full societal perspective.

\section{What this study adds}

The societal cost of AOM in the Netherlands is $€ 566$ or $\$ 639$ per episode, which is more than previously estimated. Ninety percent of costs are related to productivity losses by children's parents.

\section{Background}

With a global incidence of 10.8 episodes per 100 children each year $[1,2]$, acute otitis media (AOM) is among the most common paediatric conditions and reasons for doctors' visits, antibiotic prescribing and surgery in young children [3]. AOM is associated with considerable resource use, in healthcare and beyond [4-6].

Previous estimates of the cost of AOM do not provide the full picture $[6,7]$. In 2017, the cost of an AOM episode in the United States (US) was estimated at \$314 ( $€ 278$; currency conversion as of July 6th, 2020), but this estimate included health care resources use only [7]. A decade ago, the cost of AOM in the Netherlands and the UK was estimated at $€ 332$ and $€ 752$, respectively [6]. These figures included health care costs and patient and family costs, but not costs of productivity losses of both parents.

More important, AOM guidelines promoting more accurate diagnosis and judicious use of antibiotics, and pneumococcal conjugate vaccination, have been introduced in recent years, which may have changed the burden of AOM in terms of incidence, clinical picture and cost [8].

We therefore set out to gather robust and up-to-date estimates of the cost of AOM from a societal perspective, within the setting of a cluster randomised controlled trial of an intervention aimed at educating general practitioners (GPs) about pain management in children with AOM [9].

\section{Methods}

\section{Design and participants}

The design of the cluster randomised controlled trial and results focused on clinical effectiveness of the intervention have been reported in detail elsewhere $[9,10]$. In short, 37 GP practices were randomly assigned, using a computerised minimisation strategy, to either the intervention or the control group.GPs in practices allocated to the intervention group were offered a blended educational program (online and face-to-face training); they were trained to discuss pain management with parents using an information leaflet, and prompted to prescribe analgesics (paracetamol, and ibuprofen as add-on in case of insufficient pain relief) in weight-appropriate dosage. GPs in the practices allocated to the control group provided usual care. Management decisions, including antibiotic prescribing, were at the discretion of the GP. Children aged 6 months to 10 years with a GPconfirmed diagnosis of AOM (according to Dutch guidelines [11]) were eligible for participation, and were recruited by their GP. After inclusion, participants were followed for 28 days to capture the full range of the AOM episode, including all associated costs. The trial's primary outcome was parent-reported mean ear pain score (scale 0-10) over the first three days;

\section{Data collection}

Data on health care costs, including GP consultations, prescription medication, specialist referrals, and hospital admissions, during the 28-day follow-up period were extracted from children's primary care electronic health records. Data on patient and family costs due to the AOM episode were retrieved from diaries completed daily by the parents for the duration of follow-up. These diaries included questions on travel expenses, costs of over-thecounter (OTC) medication, and costs of childcare, related to the AOM episode. Data on productivity losses by parents of the children were retrieved from a questionnaire (iMTA Productivity Cost Questionnaire (iPCQ) [12] completed at day 28.

\section{Resource use and valuation}

Economic analyses were conducted using a societal perspective; including health care costs, patient and family costs, and costs of parental productivity losses. A detailed overview of unit costs for all cost items included in the study is shown in Table 1 and Supplementary Table 1.

Costs of prescription medication were estimated by using a publicly available Dutch database of current drug prices [13], increased with a pharmacist's charge. Costs of GP consultation, as well as hospital outpatient department (OPD) visits, emergency department (ED) visits and hospital admissions were based on Dutch 
TABLE 1 UNIT COSTS

\begin{tabular}{|c|c|c|c|c|}
\hline \multirow{2}{*}{ Resources } & \multirow[t]{2}{*}{ Unit } & \multicolumn{2}{|c|}{ Cost estimate } & \multirow[t]{2}{*}{ Source } \\
\hline & & $\bar{\epsilon}$ & $\$^{\S}$ & \\
\hline \multicolumn{5}{|l|}{ Health care costs } \\
\hline \multicolumn{5}{|l|}{ Direct costs } \\
\hline GP consultation & consultation & 33.76 & 38.11 & ZIN guideline \\
\hline GP home visit & consultation & 51.16 & 57.75 & ZIN guideline \\
\hline GP telephone & consultation & 17.39 & 19.63 & ZIN guideline \\
\hline OPD visit & visit & 81.85 & 92.39 & ZIN guideline \\
\hline ED visit & visit & 264.99 & 299.10 & ZIN guideline \\
\hline Admission & day & 453.25 & 511.59 & ZIN guideline \\
\hline Pharmacist fee & prescription & 12.28 & 13.86 & ZIN guideline \\
\hline \multicolumn{5}{|l|}{ Prescription medication } \\
\hline \multicolumn{5}{|l|}{ Antibiotics } \\
\hline Amoxicillin & prescription $^{\dagger}$ & 3.43 & 3.87 & www.medicijnkosten.nl \\
\hline Amoxicillin-clavulanate & prescription $^{\dagger}$ & 3.43 & 3.87 & www.medicijnkosten.nl \\
\hline Azitromycin & prescription $^{\dagger}$ & 3.97 & 4.48 & www.medicijnkosten.nl \\
\hline Cotrimoxazole & prescription $^{\dagger}$ & 2.81 & 3.17 & www.medicijnkosten.nl \\
\hline Clarithromycin & prescription $^{\dagger}$ & 9.51 & 10.73 & www.medicijnkosten.nl \\
\hline \multicolumn{5}{|l|}{ Ear drops } \\
\hline Otalgan ${ }^{\ominus}$ & bottle & 10.99 & 12.40 & www.medicijnkosten.nl \\
\hline Sofradex $x^{\oplus}$ & bottle & 10.56 & 11.92 & www.medicijnkosten.nl \\
\hline Ofloxacin & bottle & 0.50 & 0.56 & www.medicijnkosten.nl \\
\hline Bacicoline B drops & bottle & 14.70 & 16.59 & www.medicijnkosten.nl \\
\hline Intervention costs ${ }^{\ddagger}$ & patient & 50.85 & 57.40 & collective labour agreement for GPs \\
\hline \multicolumn{5}{|l|}{ Patient and family costs } \\
\hline \multicolumn{5}{|l|}{ Travel expenses } \\
\hline Fuel costs & kilometer & 0.19 & 0.21 & ZIN guideline \\
\hline Parking costs & visit & 3.07 & 3.47 & ZIN guideline \\
\hline \multicolumn{5}{|l|}{ Over-the-counter medication } \\
\hline Paracetamol & $1000 \mathrm{mg}$ & 1.41 & 1.59 & www.medicijnkosten.nl \\
\hline Ibuprofen & $1000 \mathrm{mg}$ & 2.50 & 2.82 & www.medicijnkosten.nl \\
\hline Otalgan ${ }^{\oplus}$ & bottle & 10.99 & 12.40 & www.medicijnkosten.nl \\
\hline Xylometazoline nasal spray & bottle & 2.08 & 2.35 & retail prices** \\
\hline Otrivin $\otimes^{\circledR}$ asal spray & bottle & 4.59 & 5.18 & retail prices** \\
\hline Sodium chloride nasal spray & bottle & 2.95 & 3.33 & retail prices** \\
\hline Complementary medicine* & bottle & $4.95-14.35$ & $5.59-16.20$ & retail prices** \\
\hline Cough syrup & bottle & 10.95 & 12.36 & retail prices ${ }^{* *}$ \\
\hline Childcare costs & one hour & 14.32 & 16.16 & ZIN guideline \\
\hline \multicolumn{5}{|l|}{ Productivity loss } \\
\hline Productivity costs father & one hour & 38.78 & 43.77 & iPCQ questionnaire \\
\hline Productivity costs mother & one hour & 32.33 & 36.49 & iPCQ questionnaire \\
\hline Unpaid work & one hour & 14.32 & 16.16 & iPCQ questionnaire \\
\hline
\end{tabular}

ED: emergency department; GP: general practitioner, iPCQ: iMTA Productivity Cost Questionnaire, mg: milligrams, OPD: out-patient department; ZIN: Zorginstituut Nederland (Netherlands Health Institute)

$\S$ currency conversion as of July 6th, 2020 ( 1 euro $=1.12872$ USD, www.xe.com/ucc)

+ one or two units per patient, depending on weight

* calculated as one-hour GP wage costs (time spent on the training) times the number of GPs in intervention group times printing costs, divided the number of patients included in the intervention group

* full display of prices of specific complementary medicine products is available online in Supplement Table 1

** prices are based on retail prices of the most used retailers in the Netherlands: Albert Heijn, Etos, Kruidvat and DA. Available from www.ah.nl, www.kruidvat.nl and www.da.nl 
guidelines for pharmacoeconomic evaluation [14]. These guidelines include reference cost figures for the use in health economic evaluations for common types of healthcare use. Using a consumer price index (CPI) [15], 2014 costs from these guidelines were corrected for inflation up to 2017, the base year for cost calculations.

Costs of OTC and complementary medication were based on average retail prices used in the Netherlands [16-18]. Childcare costs were used as reported by parents in the diary. Travel costs were based on Dutch guidelines for pharmacoeconomic evaluation, and corrected for inflation up to $2017[14,15]$.

For productivity losses, we calculated costs of absenteeism (being absent from work), presenteeism (being less productive while at work) and not being able to do unpaid work. Accumulating these three subtypes of productivity costs, we calculated a composite total productivity loss per parent caregiver.

\section{Analysis}

In the current analyses, we deviated from our initial research protocol [9] in two ways. First, considering the absence of clinical effectiveness of the intervention at trial [10], we primarily combined data from the intervention and usual care group to estimate AOM cost in the overall trial population. Second, we refrained from calculating incremental cost-effectiveness ratios (ICER) for the same reason.

Given the short-term duration of the trial, neither costs nor benefits were discounted. We imputed ten times for relevant missing data using the SPSS multiple imputation function [19], and subsequently pooled results using Rubin's rule [20].

In primary analysis, we calculated mean costs per patient with standard deviations (SD) regardless of study group assignment. In sensitivity analysis, we compared costs in the intervention and usual care group, after exclusion of extreme outliers and the intervention costs, to define whether there were significant differences between the intervention and usual care group.

All analyses were performed in SPSS version 25.0 (SPSS Inc., IBM Corporation, Chicago, IL).

\section{Results}

Between February 2015 and May 2018, 94 GPs in 37 GP practices across the Netherlands recruited 224 children (intervention $n=94$; control $n=130$ ) children aged 6 months to 10 years diagnosed with AOM and ear pain to the trial.

Table 2 shows the baseline characteristics of participating children. The baseline characteristics of GP practices (i.e. number of patients, $\%$ of patients $<10$ years, setting), individual GPs (i.e. age, experience), as well as children were generally well-balanced. Participants had a median age of 40 months (IQR 16-64 months, full range 6 months to 9 years and 10 months), $53.8 \%$ were boys. $64.6 \%$ had unilateral AOM, and $15.7 \%$ had AOM (unilateral or bilateral) with otorrhea. Most patients had had ear pain prior to consulting their GP (86.9\%) for a median of 2 days (IQR 0.5-3.5); fewer patients had had fever prior to consulting (64.3\%, median number of days 2, IQR 0.5-3.5).

Data on health care costs were available for 223 children (99.6\%). Available data on patient and family costs varied per subcategory: we had data on travel expenses for 223 children (99.5\%), on childcare costs for 162 children (72.3\%) and on OTC medication for 206 children (92.0\%). Data on productivity losses were available for 181 children (80.8\%). Some parents did not complete all questionnaires, hence the variability in missing data. Missing data appeared to be randomly divided, we had no indication for selective missing data.

Mean total cost of AOM per patient was $€ 565.93$ or $\$ 638.78$ (SD €1071.01), with high interindividual variation. Currency conversion as of July 6th, 2020 (1 euro $=1.12872$ USD, www.xe.com/ucc). Full details on costs in each category are shown in Table 3.

Mean total health care costs were $€ 77.60$ or $\$ 87.59$ (SD €160.89). The largest contributors to these costs were GP consultations and hospital admissions, at $€ 49.80$ or $\$ 56.21$ (SD $€ 1.77 ; 64.2 \%$ ) and $€ 10.16$ or $\$ 11.47$ (SD €10.16; 13.1\%) per patient, respectively. Prescription medication costs attributed for $€ 3.07$ or $\$ 3.46$ (SD $€ 0.18$; $3.9 \%)$.

Families spent on average $€ 13.07$ of $\$ 14.75$ (SD $€ 23.58)$ out of their own pocket. Main contributors were analgesics use, complementary medicine and childcare costs, at $€ 3.17$ or $\$ 3.58$ (SD $€ 2.59 ; 24.3 \%$ ), $€ 3.38$ or $\$ 3.81$ (SD $€ 12.28 ; 25.8 \%$ ) and $€ 3.17$ or $\$ 3.58$ (SD $€ 18.45$; 24.3\%) per patient, respectively.

Parental productivity losses contributed the largest share of costs, adding up to $€ 475.26$ or $\$ 536.42$ (SD $€ 1045.95)$ per patient. Overall, $56 \%$ of mothers reported productivity losses, compared to $36 \%$ of fathers. In mothers, costs were primarily related to absenteeism and unpaid work; for fathers, absenteeism was the major contributor. Productivity losses for mothers and fathers was $€ 289.16$ or $\$ 326.37$ (SD $€ 60.8 ; 25.8 \%$ of total cost) and $€ 186.09$ or $\$ 210.04$ (SD $€ 529.31 ; 39.2 \%$ of total cost) per patient, respectively.

Extreme outliers were identified in two children in the usual care group: one five-day hospitalisation for acute mastoiditis and extreme productivity losses reported by parents in another child. To study how these outliers influenced the average cost estimate, we 
TABLE 2 BASELINE CHARACTERISTICS

\begin{tabular}{|c|c|c|c|}
\hline & $\begin{array}{l}\text { Total group } \\
n=223 ; 37 \text { practices }\end{array}$ & $\begin{array}{l}\text { Intervention } \\
n=94 ; 19 \text { practices }\end{array}$ & $\begin{array}{l}\text { Usual care } \\
n=129 ; 18 \text { practices }\end{array}$ \\
\hline \multicolumn{4}{|l|}{ Characteristic } \\
\hline Age (months) ${ }^{\dagger}$ & $40(16-64)$ & $38(13-62)$ & $43(20-66)$ \\
\hline Sex (boys) & $120(53.8)$ & $54(57.4)$ & $66(51.2)$ \\
\hline \multicolumn{4}{|l|}{ Medical history } \\
\hline Recurrent AOM & $26(11.7)$ & $14(14.9)$ & $12(9.3)$ \\
\hline Recurrent URTI & $24(10.8)$ & $13(13.8)$ & $11(8.5)$ \\
\hline Previous ENT surgery & $23(10.3)$ & $15(16.0)$ & $8(6.2)$ \\
\hline Atopic constitution & $24(10.8)$ & $16(17.0)$ & $8(6.2)$ \\
\hline \multicolumn{4}{|c|}{ Symptoms prior to consultation (parent-reported) } \\
\hline Ear pain $($ yes/no)* & $166(86.9)$ & $75(90.4)$ & $91(84.3)$ \\
\hline Number of days ${ }^{\dagger}$ & $2(0.5-3.5)$ & $2(0.5-3.5)$ & $3(1-5)$ \\
\hline Otorrhoea* & $28(15.7)$ & $12(15.4)$ & $16(16.0)$ \\
\hline Number of days ${ }^{\dagger}$ & $0(0-0)$ & $2(0-5)$ & $2(0-4.5)$ \\
\hline Fever $^{*}$ & $126(64.3)$ & $50(60.2)$ & $76(67.3)$ \\
\hline Number of days ${ }^{\dagger}$ & $2(0.5-3.5)$ & $2(1-3)$ & $3(2-4)$ \\
\hline \multicolumn{4}{|l|}{ Physical examination } \\
\hline Temperature in ${ }^{\circ} \mathrm{C}^{\ddagger}$ & $37.8 \pm 1.0$ & $37.6 \pm 0.9$ & $37.9 \pm 1.1$ \\
\hline III appearance & $43(20.0)$ & $18(19.6)$ & $25(20.3)$ \\
\hline Unilateral AOM & $144(64.6)$ & $65(69.1)$ & $79(61.2)$ \\
\hline Redness & $132(59.2)$ & $60(92.3)$ & $72(91.1)$ \\
\hline Bulging & $81(36.3)$ & 29 (44.6) & $52(65.8)$ \\
\hline Otorrhoea & $12(5.4)$ & $4(6.2)$ & $8(10.1)$ \\
\hline Bilateral AOM & 79 (35.4) & $29(30.9)$ & $50(38.8)$ \\
\hline Redness & $74(33.2)$ & $29(100)$ & $45(90.0)$ \\
\hline Bulging & $53(23.8)$ & $17(58.6)$ & $36(72.0)$ \\
\hline Otorrhoea & $8(3.6)$ & $3(10.3)$ & $5(10.0)$ \\
\hline \multicolumn{4}{|l|}{ Symptoms at baseline (parent-reported) } \\
\hline Proportion of children with ear pain* & $204(98.1)$ & $87(98.9)$ & $117(97.5)$ \\
\hline Proportion of children with fever* & $107(54.9)$ & $40(48.2)$ & $67(59.8)$ \\
\hline Antibiotic prescriptions ${ }^{* *}$ & $92(41.3)$ & 36 (38.3) & $56(43.4)$ \\
\hline
\end{tabular}

Values are numbers (percentages) unless stated otherwise

${ }^{\circ} \mathrm{C}$ : degrees Celsius; AOM: acute otitis media; ENT: ear, nose, throat; GP: general practitioner; URTI: upper respiratory tract infection

${ }^{\dagger}$ median with $\mathrm{IQR},{ }^{\ddagger}$ mean with $\mathrm{SD}$

* missings: otorrhea prior to consultation (45), ear pain prior to consultation (32), fever prior to consultation (21), temperature (10), ill appearance (8), ear pain at baseline (15), fever at baseline (22)

** number (and percentage) of children prescribed one (or more) antibiotics

performed an additional analysis, from which these two subject were excluded. When excluding these children from analysis, overall mean total cost per patient was slightly lower, but still had high interindividual variation: $€ 526.70$ or $\$ 594.50$ (SD €987.96). Cost was comparable between intervention and usual care group, at $€ 516.10$ or $\$ 582.53$ (SD €949.69) and $€ 534.55$ or $\$ 603.36$ (SD $€ 920.55$ ) per patient, respectively. Supplementary Table 2 displays a comprehensive overview of costs in the separate groups.

\section{Discussion}

The cost of an AOM episode to the Dutch society were found to be $€ 566$ (\$639), of which $90 \%$ is due to productivity losses by parents. Each year, GPs diagnose 110, $000 \mathrm{AOM}$ episodes in children under the age of ten [1], which brings the total cost of AOM in the Netherlands to $€ 62.3$ million annually. The true economic burden of AOM is probably higher with one in two episodes with AOM symptoms self-managed by parent caregivers [23], although it is unclear how high productivity losses are in 
TABLE 3 USE OF RESOURCES AND MEAN COSTS (IN €) PER CHILD

\begin{tabular}{|c|c|c|c|c|}
\hline \multirow[t]{2}{*}{ Resources } & \multicolumn{4}{|l|}{ Mean costs } \\
\hline & $\begin{array}{l}\text { no. used } \\
(n, \%)\end{array}$ & $\begin{array}{l}\text { costs, in } € \\
\text { (mean } \pm S D)\end{array}$ & $\begin{array}{l}\text { costs, in \$ } \\
\text { (mean } \pm S D)\end{array}$ & \\
\hline GP consultation, initial visit & $224(100.0)$ & $33.76 \pm 0.00$ & $38.11 \pm 0.00$ & \\
\hline GP consultation, follow-up visit & $74(33.1)$ & $16.04 \pm 1.77$ & $18.10 \pm 2.00$ & \\
\hline GP home visit & $0(0)$ & $0.00 \pm 0.00$ & $0.00 \pm 0.00$ & \\
\hline GP telephone & $40(17.9)$ & $3.51 \pm 0.53$ & $3.96 \pm 0.60$ & \\
\hline OPD visit & $7(3.1)$ & $3.30 \pm 1.41$ & $3.72 \pm 1.59$ & \\
\hline ED visit & $1(0.0)$ & $1.19 \pm 1.19$ & $1.34 \pm 1.34$ & \\
\hline Admission & $1(0.0)$ & $10.16 \pm 10.16$ & $11.47 \pm 11.47$ & \\
\hline Pharmacist fee & $102(45.7)$ & $6.55 \pm 0.53$ & $7.39 \pm 0.60$ & \\
\hline \multicolumn{5}{|l|}{ Prescription medication } \\
\hline \multicolumn{5}{|l|}{ Antibiotics } \\
\hline Amoxicillin & $80(35.9)$ & $1.86 \pm 0.19$ & $2.10 \pm 0.21$ & \\
\hline Amoxicillin-clavulanate & $6(2.7)$ & $0.14 \pm 0.06$ & $0.16 \pm 0.07$ & \\
\hline Azitromycin & $6(2.7)$ & $0.14 \pm 0.06$ & $0.16 \pm 0.07$ & \\
\hline Cotrimoxazole & $2(0.01)$ & $0.03 \pm 0.02$ & $0.03 \pm 0.02$ & \\
\hline Clarithromycin & $1(0.0)$ & $0.04 \pm 0.04$ & $0.05 \pm 0.05$ & \\
\hline \multicolumn{5}{|l|}{ Ear drops } \\
\hline Otalgan ${ }^{\circledR}$ & $10(4.5)$ & $0.49 \pm 0.15$ & $0.55 \pm 0.17$ & \\
\hline Sofradex ${ }^{\circledast}$ & $3(1.3)$ & $0.24 \pm 0.14$ & $0.27 \pm 0.16$ & \\
\hline Ofloxacin & $1(0.0)$ & $0.00 \pm 0.00$ & $0.00 \pm 0.00$ & \\
\hline Bacicoline $B$ drops & $2(0.01)$ & $0.13 \pm 0.09$ & $0.15 \pm 0.10$ & \\
\hline Total healthcare costs & & $77.60 \pm 160.89$ & $87.59 \pm 181.60$ & \\
\hline \multicolumn{5}{|l|}{ Patient and family costs } \\
\hline \multicolumn{5}{|l|}{ Travel expenses } \\
\hline Fuel costs & $9(4.0)$ & $0.09 \pm 0.04$ & $0.10 \pm 0.05$ & \\
\hline Parking costs & $9(4.0)$ & $0.21 \pm 0.09$ & $0.24 \pm 0.10$ & \\
\hline \multicolumn{5}{|l|}{ Over-the-counter medication } \\
\hline Paracetamol & $191(85.7)$ & $2.55 \pm 3.10$ & $2.88 \pm 3.50$ & * \\
\hline Ibuprofen & 79 (35.4) & $0.62 \pm 1.34$ & $0.70 \pm 1.51$ & * \\
\hline Xylometazoline nasal spray & $29(13.0)$ & $0.87 \pm 2.77$ & $0.98 \pm 3.13$ & * \\
\hline Otrivin ${ }^{\circledR}$ nasal spray & $17(7.6)$ & $0.35 \pm 1.22$ & $0.40 \pm 1.38$ & * \\
\hline Sodium chloride nasal spray & $44(19.7)$ & $0.62 \pm 1.30$ & $0.70 \pm 1.47$ & * \\
\hline Complementary medicine & $33(14.8)$ & $3.38 \pm 12.28$ & $3.82 \pm 13.86$ & * \\
\hline Cough syrup & $9(4.0)$ & $1.21 \pm 7.97$ & $1.37 \pm 9.00$ & * \\
\hline Childcare costs & $27(12.1)$ & $3.17 \pm 18.45$ & $3.58 \pm 20.82$ & * \\
\hline Total patient and family costs & & $13.07 \pm 23.58$ & $14.75 \pm 26.62$ & \\
\hline \multicolumn{5}{|l|}{ Productivity loss } \\
\hline Father & 79 (35.4) & & & \\
\hline Absenteeism & & $106.13 \pm 354.05$ & $119.79 \pm 399.62$ & * \\
\hline Presenteeism & & $41.90 \pm 180.97$ & $47.29 \pm 204.26$ & * \\
\hline Unpaid work & & $38.06 \pm 173.75$ & $42.96 \pm 196.12$ & * \\
\hline Total & & $186.09 \pm 529.31$ & $210.04 \pm 597.44$ & * \\
\hline
\end{tabular}


TABLE 3 USE OF RESOURCES AND MEAN COSTS (IN €) PER CHILD (Continued)

\begin{tabular}{|c|c|c|c|c|}
\hline \multirow[t]{2}{*}{ Resources } & \multicolumn{4}{|c|}{ Mean costs } \\
\hline & $\begin{array}{l}\text { no. used } \\
(n, \%)\end{array}$ & $\begin{array}{l}\text { costs, in } € \\
(\text { mean } \pm \text { SD) }\end{array}$ & $\begin{array}{l}\text { costs, in \$ } \\
(\text { mean } \pm \text { SD) }\end{array}$ & \\
\hline Mother & $126(56.5)$ & & & \\
\hline Absenteeism & & $139.74 \pm 637.66$ & $157.73 \pm 719.74$ & * \\
\hline Presenteeism & & $52.50 \pm 217.53$ & $59.26 \pm 245.53$ & * \\
\hline Unpaid work & & $96.92 \pm 256.35$ & $109.40 \pm 289.35$ & * \\
\hline Total & & $289.16 \pm 786.73$ & $326.38 \pm 888.00$ & * \\
\hline Total productivity losses ${ }^{\ddagger}$ & & $475.26 \pm 1045.94$ & $536.44 \pm 1180.57$ & \\
\hline \multicolumn{5}{|l|}{ Total } \\
\hline Total healthcare costs & & $77.60 \pm 160.89$ & $87.59 \pm 181.60$ & \\
\hline Total patient costs & & $13.07 \pm 23.58$ & $14.75 \pm 26.62$ & \\
\hline Total productivity losses & & $475.26 \pm 1045.94$ & $536.44 \pm 1180.57$ & \\
\hline Total costs & & $565.93 \pm 1071.01$ & $638.78 \pm 1208.87$ & \\
\hline
\end{tabular}

ED: emergency department; GP: general practitioner, OPD: out-patient department, SD: standard deviation

${ }^{+}$one admission for mastoiditis (duration: 5 days)

* Per child, calculated as productivity losses of mother and/or father combined

*missing values were imputed

parents self-managing AOM episodes (presumably lower than in those consulting their GP).

Our cost estimate of $€ 566$ per AOM episode is higher than the $€ 332$ (2020: $€ 270$ after adjustment for inflation and purchasing power) $[15,24]$ that was described about a decade ago [6]. This difference may be related to our more accurate method of cost data collection: we collected detailed cost data prospectively over 28 days post AOM diagnosis by a parent diary and questionnaire whereas Wolleswinkel et al [6] gathered retrospective estimates from parents participating in a consumer panel. Furthermore, this difference may be explained by a change in incidence and burden of disease, as recent years saw guidelines $[11,25,26]$ introduced that promote more accurate diagnosis and judicious use of antibiotics as well as the introduction of the pneumococcal conjugate vaccination. This may have resulted in a higher proportion of more severe AOM cases that are presented to clinicians, with milder cases self-managed by parents at home.

From an international perspective, our cost estimate of $€ 566$ is lower than one found in the UK (€752, 2020: $€ 910$ after adjustment) [6, 15, 24]. Apart from differences in cost data collection, UK costs are higher due to higher costs of medical facilities, and due to a larger proportion of children experiencing symptoms of AOM presenting to emergency hospital services as well as higher antibiotic prescription rates $[6,27]$. United States data available so far include only cost of health care resource use for AOM and in light of our results represent an underestimate of the true cost of AOM to societies [4].

Our cost estimates show a high interindividual variation, both in the primary analysis, as well as in the sensitivity analysis in which we exclude two outliers with considerable resource use. This interindividual variation was largely a consequence of a variation in parental productivity loss (see Table 3), with some parents reporting very little absence (or reduced productivity at work), but others considerable productivity loss.

\section{Strengths and limitations}

This economic analysis provides a detailed and up-to-date account of the cost of childhood AOM in the Netherlands from a societal perspective; we prospectively collected detailed cost data using a daily symptom diary including a productivity loss questionnaire, and review of medical records. Although this cost study was embedded in a trial, we are confident that our estimates reflect those experienced in day-to-day practice in the Netherlands because [1] our pragmatic RCT left most treatment decisions at the GP's discretion and [2] the clinical course of AOM in children in our study match previous studies [21, 28]. The intervention at trial had no effect on clinical outcomes and AOM cost were similar in the intervention and control group. The antibiotic prescription rate was lower in our trial context than in standard Dutch practice $(41.3 \%$ vs. 55.0\%), but similar in both treatment groups. Hence, the presented cost figures might be slightly lower than in daily Dutch practice, although the cost of prescription medication is minimal compared to overall cost.

This study has some limitations. AOM cost estimates are a reflection of countries' health care systems and practices. Dutch GPs act as 'gatekeepers' to the healthcare system both in and out of office-hours; they manage all cases of AOM initially, and only refer to secondary care in case of complications. This is different from 
many other countries, where for example AOM is managed predominantly by community paediatricians or emergency hospital services [6, 7]. Importantly, for decades, Dutch GPs have practiced a watchful waiting strategy for AOM, resulting in half the antibiotic prescriptions compared to the UK (72.5 vs. 164 per 1000 child years) [22, 27]. In the US, $86 \%$ of doctor consultations for AOM ends with an antibiotic prescription [29]. Concerning study methods, some cost data were missing at-random in our study $(10 \%$ for OTC medication, $19.2 \%$ for productivity loss, and $27.7 \%$ for childcare costs). We used multiple imputation techniques to handle these missing data, and minimise the impact on our analysis [20]. Furthermore, data on symptoms and resource use during follow-up were captured from parentreported surveys in a patient diary, which parents filled in every day. Resources use (i.e. antibiotic and medication use, as well as GP and hospital visits) were crosschecked by collecting these from the patients' medical files. As such, we have aimed to minimise the risk of recall bias. We captured parental productivity loss through a questionnaire that parents filled in at the end of the 28-day follow-up, risk of recall bias cannot be excluded for this questionnaire.

\section{Conclusions}

At $€ 566$ per episode, and an estimated $€ 62$ million annually, societal cost of AOM is higher than previously known and mainly driven by productivity losses by children's caregivers. Considering its high incidence, AOM poses a significant economic burden to society that extends beyond medical costs, close to $€ 62$ million annually in the Netherlands alone.

\section{Supplementary Information}

The online version contains supplementary material available at https://doi. org/10.1186/s12913-021-06157-1.

Additional file 1: Supplementary Table 1. Complementary medicine unit costs.

Additional file 2: Supplementary Table 2. Sensitivity analysis 1. Use of resources and mean costs (in €) per child (imputed, two outliers excluded).

\section{Abbreviations \\ AOM: Acute otitis media; CPI: Consumer price index; ED: Emergency department; ENT: Ear, nose, throat; GP: General Practitioner; ICER: Incremental cost-effectiveness ratio; ILI: Influenza-like illness; iPCQ: IMTA Productivity Cost Questionnaire; OPD: Out-patient department; PIM-POM: Pain Intensity Monitoring in Paediatric Otitis MediaSDStandard deviation; UK: United Kingdom; US : United States}

\section{Acknowledgements}

The authors would like to thank all general practitioners, parents and children who participated in this study.

Consent to publication

Not applicable.

\section{Authors' contributions}

RPV, AGMS and RAMJD conceptualized and designed the trial and acquired funding. AS and ACvdP drafted the first version of the study protocol, and RPV, AGMS and RAMJD provided feedback hereon. AS and RTVU recruited GP practices to the trial and were responsible for data collection and storage, under the supervision of RPV, AGMS and RAMJD. RTVU, CTBP, GAdW and RPV performed all analyses, and RTVU and RPV drafted the first version of the manuscript, CTBP, GAdW, AS, ACvdP, AGMS and RAMJD provided feedback on the manuscript. All authors approved the final version of the manuscript. The lead author (the manuscript's guarantor) affirms that the manuscript is an honest, accurate, and transparent account of the study being reported; that no important aspects of the study have been omitted; and that any discrepancies from the study as originally planned (and, if relevant, registered) have been explained.

\section{Funding}

This trial was supported by a grant from the Netherlands Organisation for Health Research and Development (ZonMw) - HGOG subprogramme (project number 839110005). The funding agency had no role in the study design, data collection and analysis, decision to publish, or preparation of the manuscript.

\section{Availability of data and materials}

Data generated during the study will be made available from the corresponding author on reasonable request.

\section{Ethics approval and consent to participate}

The trial was conducted according to the principles of the Declaration of Helsinki (10th version, October 2013) [30] and the Dutch Conduct Code for Health Research (Gedragscode Gezondheidsonderzoek "Goed Gedrag") [31] The Medical Ethics Review Committee of the University Medical Center Utrecht, the Netherlands, reviewed the study protocol (protocol WAG/om/ 14/021633) and confirmed that official approval was not required: the Medical Research Involving Human Subjects Act (WMO) does not apply to our trial as participation in the study does not add to the risks inherent to the condition (AOM) and its management in Dutch primary care. The study was monitored by an independent data monitor to ensure the quality of trial execution. All patients provided full written informed consent to participate in the trial.

\section{Competing interests}

None of the authors have financial and non-financial competing interests that may be relevant to the submitted work.

\section{Author details}

'Julius Center for Health Sciences and Primary Care, University Medical Center Utrecht, University Utrecht, P.O. Box 85500, 3508, GA, Utrecht, The Netherlands. ${ }^{2}$ Centre for Nutrition, Prevention and Healthcare, National Institute of Public Health and the Environment, Bilthoven, The Netherlands. ${ }^{3}$ evidENT, Ear Institute, University College London, London, UK. ${ }^{4}$ National Institute for Health Research, University College London Hospitals Biomedical Research Centre, London, UK.

Received: 16 July 2020 Accepted: 8 February 2021

Published online: 04 March 2021

\section{References}

1. van der Linden MW, van Suijlekom-Smit LWA, Schellevis FG, van der Wouden JC. [Second national study of diseases and procedures in general practice: the child in general practice]. Utrecht: NIVEL; 2015.

2. Monasta L, Ronfani L, Marchetti F, Montico M, Brumatti L, Bavcar A, et al. Burden of disease caused by otitis media: systematic review and global estimates. PLoS One. 2012;7(4):e36226.

3. Marom T, Tan A, Wilkinson GS, Pierson KS, Freeman JL, Chonmaitree T. Trends in otitis media-related health care use in the United States, 20012011. JAMA Pediatr. 2014;168(1):68-75.

4. Tong S, Amand C, Kieffer A, Kyaw MH. Trends in healthcare utilization and costs associated with pneumonia in the United States during 2008-2014. BMC Health Serv Res. 2018;18:318.

5. Sun D, McCarthy TJ, Liberman DB. Cost-effectiveness of watchful waiting in acute otitis media. Pediatrics. 2017;139(4):e20163086. 
6. Wolleswinkel-van den Bosch JH, Stolk EA, Francois M, Gasparini R, Brosa M The health care burden and societal impact of acute otitis media in seven European countries: results of an internet survey. Vaccine. 2010;28S:G39-52.

7. Ahmed S, Shapiro NL, Bhattacharyya N. Incremental health care utilization and costs for acute otitis media in children. Laryngoscope. 2014;124(1):301-5.

8. Gisselsson-Solen M. Trends in otitis media incidence after conjugate pneumococcal vaccination: a National Observational Study. Pediatr Infect Dis J. 2017;36(11):1027-31.

9. van Uum RT, Venekamp RP, Sjoukes A, van der Pol AC, de Wit AG, Schilder $A G$, et al. Optimising pain management in children with acute otitis media through a primary care-based multifaceted educational intervention: study protocol for a cluster randomised controlled trial. Trials. 2018;19(501):1-9.

10. van Uum RT, Venekamp RP, Zuithoff NPA, Sjoukes A, van de Pol AC, de Wit $A G$, et al. Improving pain management in childhood acute otitis media in general practice: a cluster randomised controlled trial of a GP-target educational intervention. Br J Gen Pract. 2020;70(699):e684-95.

11. Damoiseaux RA, Venekamp RP, Eekhof J, Bennebroek Gravenhorst F, Schoch A, Burgers J, et al. [M09 NHG guideline Acute Otitis Media in children]. Huisarts Wet. 2014;57(12):648.

12. Bouwmans M. [Handleiding iMTA Productivity Cost Questionnaire (iPCQ)] [Internet]. Rotterdam: institute for Medical Technology Assessment, Erasmus University; 2013. Available from: https://www.imta.nl/questionnaires/

13. Zorginstituut Nederland. Medicijnkosten.nl [Internet]. 2020 [cited 6 July 2020]. Available from: www.medicijnkosten.nl.

14. Zorginstituut Nederland. Guideline for the execution of economic analyses in healthcare. Zorginstituut Nederland: Diemen; 2016. p. 1-38.

15. CPI database [Internet]. 2020 [cited 6 July 2020]. Available from: https:// opendata.cbs.nl/statline/\#/CBS/nl/dataset/83131NED/table?ts=153794841 8755.

16. DA drogisterij [Internet]. 2020 [cited 6 July 2020]. Available from: www.da.nl.

17. Albert Heijn / Etos [Internet]. 2020 [cited 6 July 2020] Available from: www. da.nl.

18. Kruidvat [Internet]. 2020 [cited 6 July 2020]. Available from: www.da.nl.

19. Donders ART, van der Heijden GJMG, Stijnen T, Moons KGM. Review: a gentle introduction to imputation of missing values. J Clin Epidemiol 2006; 59(10):1087-1091.

20. Rubin D. Multiple imputation for non-response in surveys. New York: John Wiley; 1987.

21. Little P, Gould C, Williamson I, Moore M, Warner G, Dunleavey J. Pragmatic randomised controlled trial of two prescribing strategies for childhood acute otitis media. BMJ. 2001;322:336-42.

22. Dekker ARJ, Verheij TJM, van der Velden AW. Antibiotic management of children with infectious diseases in Dutch primary care. Fam Pract. 2017; 34(2):169-74.

23. Fortanier AC, Venekamp RP, de Hoog MLA, Uiterwaal CSPM, van der Gugten AC, van der Ent CK, et al. Parent-reported symptoms of acute otitis media during the first year of life: what is beneath the surface? PLoS One. 2015; 10(4):e0121572.

24. Drummond M, Sculpher M, Claxton K, Stoddart G, Torrance G. Methods for the economic evaluation of health care programmes. Oxford: Oxford University Press; 2015.

25. NICE. Otitis media (acute): antimicrobial prescribing (NG91) [internet]. NICE 2018. Available from: nice.org.uk/guidance/ng91.

26. Lieberthal AS, Carroll AE, Chonmaitree T, Ganiats TG, Hoberman A, Jackson MA, et al. Clinical practice guideline: the diagnosis and Management of Acute Otitis Media. Pediatrics. 2013;131:e964-99.

27. Thompson PL, Gilbert RE, Long PF, Saxena S, Sharland M, Wong ICK. Has UK guidance affected general practitioner antibiotic prescribing for otitis media in children? J Public Health (Bangkok). 2008;30(4):479-86.

28. Rovers MM, Glasziou P, Appelman CL, Burke P, McCormick DP, Damoiseaux RA, et al. Antibiotics for acute otitis media: a meta-analysis with individual patient data. Lancet. 2006;368:1429-35.

29. Suaya JA, Gessner BD, Fung S, Vuocolo S, Scaife J, Swerdlow DL, et al. Acute otitis media, antimicrobial prescriptions, and medical expenses among children in the United States during 2011-2016. Vaccine. 2018;36:7479-86.

30. World Medical Association. WMA declaration of Helsinki - ethical principles for medical research involving human subjects [internet]. Fortaleza, Brazil: World Medical Association; 2013. Available from: https://www.wma.net/ policies-post/wma-declaration-of-helsinki-ethical-principles-for-medical-resea rch-involving-human-subjects/
31. Gedragscode Gezondheidsonderzoek (Dutch Conduct Code for Health Research) [Internet]. Rotterdam, the Netherlands: Stichting Federatie van Medisch Wetenschappelijke Vereniging (Dutch Federation of Biomedical Science Associations); 2005. Available from: https://www.federa.org/sites/ default/files/bijlagen/coreon/gedragscode_gezondheidsonderzoek.pdf

\section{Publisher's Note}

Springer Nature remains neutral with regard to jurisdictional claims in published maps and institutional affiliations.
Ready to submit your research? Choose BMC and benefit from:

- fast, convenient online submission

- thorough peer review by experienced researchers in your field

- rapid publication on acceptance

- support for research data, including large and complex data types

- gold Open Access which fosters wider collaboration and increased citations

- maximum visibility for your research: over $100 \mathrm{M}$ website views per year

At BMC, research is always in progress.

Learn more biomedcentral.com/submissions 